\title{
Desigualdades de género en los discursos de la dirigencia sindical argentina. Estudio de caso en el sector salud
}

\author{
Gender inequalities in the discourses of the union \\ leaders in Argentina. Case Study in the health sector
}

\section{Eliana Laura Aspiazu*}

Perfiles Latinoamericanos, 27(53) | 2019

DOI: $10.18504 / \mathrm{pl} 2753-008-2019$

Recibido el 18 de octubre de 2016

Aceptado el 23 de julio de 2018

\section{Resumen}

En un contexto donde la creciente participación laboral y sindical de las mujeres coexiste con múltiples situaciones de inequidad y discriminación, este artículo busca identificar el grado de reconocimiento y comprensión por parte de la dirigencia sindical argentina sobre las desigualdades de género, analizando aspectos culturales y subjetivos de la problemática. Para ello, se utiliza la metodología cualitativa de estudio de casos en dos sindicatos de la salud, por ser una de las actividades más feminizadas donde la proporción de mujeres no se ve reflejada ni en la representación sindical ni en las políticas gremiales.

\begin{abstract}
In a context of increasing labor and union participation of women that coexists with multiple situations of inequality and discrimination, this article seeks to identify the degree of recognition and understanding on the part of the Argentine trade union leadership about gender inequalities, analyzing cultural and subjective aspects of the problem. The empirical study is based on qualitative case study methodology in health unions in Argentina, which is one of the most feminized activities where the proportion of women is not reflected either in union representation or the trade policies.
\end{abstract}

Palabras clave: igualdad de género, mujeres en los sindicatos, cultura sindical, discursos, sindicalismo, sector salud, Argentina.

Keywords: Gender equality, women in trade unions, union culture, discourses, trade-unionism, health sector, Argentina.

* Doctora en Ciencias Sociales y Humanas por la Universidad Nacional de Quilmes. Docente e investigadora en el Grupo de Estudios del Trabajo de la Facultad de Ciencias Económicas y Sociales de la Universidad Nacional de Mar del Plata | eliaspiazu@yahoo.com.ar 


\section{Introducción}

E

sindicalismo es uno de los ámbitos fundamentales con los que cuentan los trabajadores y trabajadoras para agruparse y defender sus intereses y sus derechos colectivamente. En las últimas décadas, ha tenido que modificarse y adaptarse a las nuevas realidades del mundo del trabajo, el cual ha tenido profundas transformaciones, entre ellas, la creciente incorporación de las mujeres, la cual coexiste con profundas injusticias e inequidades de género.

Las estadísticas disponibles para Argentina muestran la persistencia, y a veces profundización, de desigualdades en el mercado laboral, en el espacio doméstico y en los ámbitos político y sindical, que posicionan a las mujeres en una situación de desventaja y subordinación respecto de los varones. Según datos de 2016 de la Encuesta Permanente de Hogares del Instituto Nacional de Estadística y Censos (INDEC), las mujeres actualmente siguen participando mucho menos que los varones en el mercado laboral: la tasa de actividad femenina alcanza al $47.1 \%$ mientras que la masculina se eleva a $71.9 \%$. Además, las mujeres tienen más probabilidad que los varones de sufrir situaciones de desempleo: la tasa de desempleo es de $8.6 \%$ y $6.5 \%$, respectivamente. Esta menor participación de las mujeres en el mercado laboral se explica por determinantes socioeconómicos, lo que demuestra la interrelación entre las cuestiones de género y de clase. Adicionalmente, las mujeres insertas en el mercado laboral se concentran en las actividades peor remuneradas, menos calificadas y más desprotegidas en términos de derechos laborales y representación sindical, como el servicio doméstico que alcanza un $80 \%$ de empleo informal.

Dadas las múltiples formas que adquiere actualmente el trabajo, la creciente diversidad del universo de las trabajadoras y los trabajadores, y que gran parte de las problemáticas del mundo laboral tienen un efecto diferente sobre los varones y sobre las mujeres, resultando en inequidades como las mencionadas, observar las diferencias desde una perspectiva de género resulta insoslayable. En este sentido, nos preguntamos ¿cuáles son las condiciones que deben darse para avanzar en esa dirección? ¿Es posible generar mecanismos y estrategias de equidad que afecten a la población trabajadora, si al interior de las propias estructuras sindicales se reproducen y se naturalizan las desigualdades de género?

La problemática de género ha sido reconocida por los actores sindicales en Argentina, al menos en lo formal, a través de herramientas institucionales como la creación de secretarías o áreas de género y la aplicación de la Ley de Cupo Sindical Femenino (No 25674), que promueve la participación de las mujeres en los sindicatos, la creación de secretarías o áreas específicas que se ocupan de temas de género y, con menor frecuencia, la incorporación de la temática en 
la formación sindical (Aspiazu, 2014, 2016). Sin embargo, aún es incipiente la inclusión de temas vinculados a la igualación de derechos y oportunidades entre varones y mujeres en la agenda sindical, como mostraron algunos estudios sobre el tema (Abramo \& Rangel, 2003; Bonaccorsi \& Carrario, 2012; Díaz \& Goren, 2011; Iranzo \& Richter, 2003; Lupica, 2010; Rigat, 2008a, 2008b; Novick, Trajtenberg \& Heredia, 2005; Trajtemberg, 2009). Asimismo, el aumento en la cantidad de mujeres que ocupan lugares de dirigencia no ha resultado en un reparto equitativo del poder con los varones, ni ha modificado los mecanismos de discriminación, ni se han logrado instalar de forma permanente las problemáticas de género en la agenda sindical o en el ámbito de la negociación colectiva y de las demandas disputadas en los conflictos laborales.

Si bien en lo formal se ha comenzado a institucionalizar la problemática de género, en la práctica concreta de muchas organizaciones su incorporación sigue siendo incipiente, lo cual puede identificarse en los discursos de la dirigencia sindical y en el modo de construir y ejercer el poder en los gremios. Aún persisten mecanismos que invisibilizan y naturalizan las desigualdades de género, obstaculizando la instalación de la problemática de manera transversal en la política sindical.

En ese sentido, el objetivo de este artículo es identificar el grado de reconocimiento y comprensión por parte de las y los dirigentes sindicales sobre las desigualdades de género existentes en los ámbitos laboral y gremial. Considerando dicho reconocimiento como un paso necesario para la inclusión de la perspectiva de género y la implementación de políticas sindicales que aporten al cambio.

En este artículo, se aborda dicha problemática desde una estrategia metodológica cualitativa de estudio de casos, a partir de la cual nos adentramos en la práctica de dos sindicatos con gran representatividad en el sector salud en Argentina: la Asociación de Profesionales de la Salud de la Provincia de Buenos Aires (CICOP) y la Federación de Trabajadores de la Sanidad Argentina (FATSA). Se realizaron treinta entrevistas en profundidad a dirigentes sindicales varones y mujeres de ambos gremios, durante 2014 y 2015.

La salud es una actividad compuesta mayormente por mujeres, que a la vez presenta profundas inequidades de género en el empleo, las cuales han sido ampliamente evidenciadas en estudios previos (Aspiazu, 2016a; Novick \& Galín, 2003; Pautassi, 2006; Wainerman \& Geldstein, 1990); sumado a que el sistema de representación sindical sectorial no refleja la alta proporción de mujeres en sus estructuras ni en los contenidos de sus políticas (Aspiazu, 2016b). Estas características hacen del sector de la salud un ámbito particularmente pertinente para el análisis de los discursos sobre las desigualdades de género, a modo de caso testigo de las limitaciones y posibilidades para el desarrollo de un sindicalismo con perspectiva de género. 


\section{El abordaje multidimensional del género: aspectos estructurales, culturales y simbólicos en la construcción de desigualdades de género}

Las organizaciones sindicales y las instituciones laborales, en general, forman parte de un entramado institucional que reproduce, y muchas veces profundiza, las desigualdades de género. El estudio de las instituciones y las normas sociales que producen y reproducen dichas desigualdades representa un elemento fundamental de cualquier conceptualización del género, tal como lo plantearon muchas investigadoras feministas (Ariza \& De Oliveira, 1999; De Barbieri, 1996; Lamas, 1999; Ledwith, 2012; Okin, 1989; Pastor, 1994; Scott, 1990; Todaro, 2004).

Instituciones, normas, cultura, lenguaje y poder son dimensiones fundamentales en la constitución de las relaciones sociales de género. La interrelación entre estos factores ocurre en todos los aspectos de la vida social, política y cultural e influye ampliamente en la constitución de la identidad y la subjetividad de las personas. Cada uno de nosotros, mujeres y varones, cumplimos diferentes roles según el ámbito en el que nos desenvolvemos y, en todos, la diferencia de género está presente, condicionándonos y condicionando nuestras relaciones, la división del trabajo y las percepciones que tenemos sobre nosotros mismos y sobre los otros.

La identidad de género se construye a lo largo de toda la vida a partir de las definiciones sociales y de las autodefiniciones que la persona va elaborando, como varón o como mujer, y tiene un doble carácter: de identificación con modelos y de rechazo a lo que no corresponde a la identidad en construcción. Todo ello crea un sistema de distinciones entre géneros y de percepción de semejanzas dentro de cada uno (Tobío, 2012). La cultura, los símbolos y los significados en torno al género son tan importantes como la dimensión de la subjetividad, de la identidad y de la construcción de sentido para comprender el modo como los actores sociales aprehenden las diferencias de género y la diferencia sexual en los distintos ámbitos de interacción social. En las ciencias sociales se han desarrollado numerosas definiciones del concepto de género que apuntan a poner de manifiesto, cuestionar y comprender las desigualdades sociales, culturales, políticas y económicas entre varones y mujeres. Joan Scott (1990: p. 44) lo definió como "un elemento constitutivo de las relaciones sociales basadas en las diferencias que distinguen los sexos" y como "una forma primaria de relaciones significantes de poder". Concebir el género como una construcción social compleja y como una relación de poder que incluye el conflicto, permitió comprender que se trata de una relación social dinámica, capaz de cambiar y de generar transformaciones sociales (De Barbieri, 1996).

¿Por qué resulta importante analizar una problemática social desde la perspectiva de género? Principalmente, para analizar cómo dicha problemática afecta 
de modo diferencial a varones y mujeres en una misma sociedad, en tanto que posibilita deconstruir la legitimación y consolidación histórica de las desigualdades sociales fundadas en "lo biológico"; que en las sociedades occidentales se caracteriza por asignar menor valor y jerarquía a lo femenino. Asimismo, su importancia radica en que permite pensar soluciones, políticas y herramientas para enfrentar la desigualdad, teniendo en cuenta las necesidades particulares y pensando en soluciones que aporten a la justicia y a la equidad.

Es importante destacar el lugar preponderante que ocupan las dimensiones de la cultura, de la subjetividad y de los discursos en la construcción de sentido en torno a la diferencia de género. La vasta producción bibliográfica, que resultó de la investigación y el debate en torno al género en las ciencias sociales, muestra que mujeres y varones no tienen "esencias" diferentes que se deriven de características biológicas, sino que las diferencias son construcciones simbólicas pertenecientes al orden del lenguaje y de las representaciones (De Barbieri, 1996; Lamas, 1999, 2000; Okin, 1989; Pastor, 1994; Scott, 1990, entre otras). La importancia de la cultura, los símbolos y los significados en torno al género, jerarquizan la dimensión de la subjetividad y la construcción de sentido para comprender el modo como los actores sociales aprehenden las diferencias de género y la diferencia sexual en los distintos ámbitos de acción e interacción social.

En cada cultura una operación simbólica básica otorga cierto significado a los cuerpos de las mujeres y de los hombres, y va construyendo socialmente la masculinidad y la feminidad. Comprender cómo han sido inscritas, representadas y normadas la feminidad y la masculinidad implica analizar las prácticas simbólicas y los mecanismos culturales que reproducen el poder a partir del eje de la diferencia anatómica entre los sexos. "Esto requiere decodificar significados y metáforas estereotipadas, cuestionar el canon y las ficciones regulativas, criticar la tradición y las resignificaciones paródicas" (Lamas, 2000: pp. 9-10). En este sentido, y retomando algunos conceptos de Bourdieu (1997), Lamas explica que las mujeres y los varones no son un reflejo de la realidad "natural", sino que son el resultado de una producción histórica y cultural, basada en el proceso de simbolización, y que como "productores culturales" desarrollan un sistema de referencias comunes.

Para comprender la realidad social en clave de género, siguiendo a Bourdieu $(1991,1997,2000)$, es necesario reconstruir el modo como se simboliza la oposición hombre/mujer mediante articulaciones metafóricas e institucionales, exponiendo la forma en que opera la distinción sexual en todas las esferas de la vida social y el orden representacional, y cómo es el proceso de introyección del género. Las diferencias entre los sexos están inmersas en el conjunto de oposiciones que organizan la división de tareas y actividades y los roles sociales y, 
al estar construidas sobre la diferencia anatómica, esas oposiciones confluyen para sostenerse al mismo tiempo que los esquemas de pensamiento las registran como diferencias naturales. Las personas aprehenden esa división básica entre lo femenino y lo masculino mediante las actividades cotidianas, las cuales están totalmente cargadas de sentido simbólico. Es en la práctica cotidiana donde los conceptos sobre lo masculino y lo femenino, establecidos como un conjunto objetivo de referencias, estructuran la percepción y la organización concreta y simbólica de toda la vida social (Bourdieu, 2000).

Bourdieu advierte que la fuerza del orden social masculino radica en que está tan profundamente arraigado que no requiere justificación: la visión androcéntrica se impone como neutra y no siente la necesidad de enunciarse en discursos que la legitimen. Lamas (2000) advierte que este planteo de Bourdieu posiciona a la violencia simbólica como un mecanismo opresor sumamente eficaz precisamente por la introyección que las personas hacen del género.

En este punto, el planteo se torna polémico en vinculación con la teoría feminista, dado que para Bourdieu las estructuras dominantes respecto del sexo, que ya están interiorizadas como ley social incorporada, no pueden ser anuladas por medio de la voluntad o la toma de conciencia liberadora pues ya están inscritas en los cuerpos e incluso pueden sobrevivir mucho tiempo luego de la desaparición de sus condiciones sociales de producción. La dominación así vista es imbatible, pues se ha biologizado en los cuerpos y en las mentes y Bourdieu no explicita una salida o una explicación a los mecanismos de quebrantamiento de esas estructuras (Sandoval, 2002). No obstante, tampoco sostiene explícitamente que el cambio sea imposible, por lo tanto, resulta de interés rescatar otras posturas complementarias que nos permitan pensar una posible ruptura con los mecanismos de dominación y plantear el cambio como un proceso posible.

En este sentido, retomamos dos conceptos que incorpora Zemelman (1994) como ideas clave para pensar la posibilidad de cambio: la existencia de sujetos emergentes y de puntos de intersticio en la realidad. Ambos conceptos apuntan a explicar que no hay ninguna realidad suficientemente ordenada, ni poder lo suficientemente monolítico, que impida la existencia de espacios intersticiales desde los cuales poder influir en el rumbo que tomen los procesos sociohistóricos y desde donde se pueda actuar de una manera distinta a como quiere mandar y normar el discurso dominante. $Y$ ahí se encuentra el desafío.

Asimismo, Touraine (1997) sostiene que afirmarse como sujeto significa tener la capacidad para reflexionar sobre sí mismo, para poder reconocerse en la vida que cada uno controla pero que al mismo tiempo nos es impuesta por nacimiento. Ser sujeto es también afirmarse como creador de sentido y de cambio, de relaciones sociales, de instituciones políticas. El sujeto actual reivindica su derecho a la existencia individual y a ser actor de su propia vida y en 
este proceso transforma la sociedad, muchas veces sin darse cuenta. Pensándolo directamente en relación a la dominación de género, Bonder (1998: p. 13) sostiene que la historia demuestra que existen posibilidades de resistencia, "los sujetos resisten, resignifican y crean nuevas representaciones y prácticas sociales vis á vis los diferentes órdenes discursivos y dispositivos institucionales que a su vez los han constituido".

Con base en los planteos precedentes, sostenemos que el orden social y las relaciones de género son tan fuertes que se imponen a los sujetos como un orden establecido, en el cual los roles se naturalizan, se hacen cuerpo, son legitimados por símbolos, discursos y normas culturales, generando cierta predisposición a actuar, sentir y pensar de un modo determinado. Sin embargo, nos posicionamos en la idea de que a pesar de la fuerza de dicho orden social, siempre existe una posibilidad de resistencia, de toma de conciencia frente a lo impuesto, un modo de desnaturalizar y cuestionar el orden establecido.

Pensamos el cambio como un proceso histórico, cultural y social que se va dando en diferentes planos, entre ellos en las relaciones de género, que si bien es lento, hay indicios significativos de su existencia a lo largo de la historia, como consecuencia del conflicto, la lucha y la resistencia, inherentes a la vida en sociedad.

\section{La cultura sindical atravesada por desigualdades de género}

El ámbito sindical representa un contexto institucional y normativo particular, con reglas, costumbres y rasgos culturales propios, donde existen sistemas de representaciones que definen roles e identidades diferentes para mujeres $\mathrm{y}$ varones.

En lo institucional, tanto en nuestros casos de estudio como en el sindicalismo argentino en general, ha habido algunos avances para las mujeres en la actividad gremial. Por un lado, su mayor participación, como consecuencia de la aplicación de la Ley de Cupo Sindical Femenino que obliga a un mínimo de $30 \%$ de mujeres en los cargos electivos. En uno de nuestros casos de estudio, el cicop, esa representación se eleva al menos al 50\% ya que se estableció la paridad de la representación entre varones y mujeres en todas las comisiones directiva. Por otro lado, la creación de áreas especializadas en temas de género, que están presentes en la mayoría de las organizaciones. Por ejemplo, en el Cicop como Secretaría de Igualdad de Oportunidades y Género y en Sanidad como Secretaría de la Mujer.

Sin embargo, aún falta mucho camino por andar y el recorrido es sinuoso, con avances y retrocesos y con múltiples obstáculos. La inclusión de contenidos 
de género en la negociación colectiva es muy escasa y la relación entre la cantidad de mujeres trabajadoras y de dirigentes sindicales en puestos de decisión no es proporcional, ya que siguen siendo minoritarias incluso en las actividades más feminizadas. En Argentina, los tres sectores con mayor tasa de afiliación de mujeres a los sindicatos —enseñanza (75\%), salud (55\%) y administración pública (46\%) — en los puestos de dirección sindical sostienen una fuerte primacía masculina: en la administración pública las mujeres ocupan apenas 16 de 158 secretarías generales relevadas; en enseñanza las mujeres ocupan la secretaría general solo en 22 de los 58 sindicatos sobre los que pudo obtenerse información sobre composición por sexo; en salud las mujeres ocupan 12 de las 41 secretarías generales identificadas. La brecha resultante entre la proporción de directivas mujeres y directivos hombres es de 11.3 para la administración pública, de $61.1 \%$ en la educación y de $41.4 \%$ en el sector salud, según datos de la Base de Asociaciones Sindicales del Ministerio de Trabajo, Empleo y Seguridad Social de la Nación (Libchaber de Palomino, 2011).

Pero ¿¿cuáles son las limitaciones? ¿Qué factores dificultan un cambio que lleve al sindicalismo a ser un espacio más igualitario en términos de género y que la búsqueda de dicha igualdad sea considerada una política gremial con igual importancia que las demás?

Parafraseando a Acker (1990: pp. 251-252), quien desarrolló la teoría de las organizaciones atravesadas por el género o generizadas (gendered organizations), entendemos que este se encuentra presente y escondido incluso en los procesos y decisiones que no parecen tener nada que ver con el género. Siguiendo su teoría, identificamos cuatro grupos interrelacionados de procesos que se visibilizan en las organizaciones y que son clave en la reproducción de estereotipos y roles de género: la construcción de divisiones entre varones y mujeres, donde los varones casi siempre están en las posiciones más altas del poder; la construcción de símbolos e imágenes que explican, expresan, refuerzan y a veces oponen esas divisiones, tales como el lenguaje, la vestimenta y el discurso mediático; ciertas interacciones entre mujeres y varones que incluyen sexismo y acoso sexual, y los componentes de género de la identidad individual y de la representación que cada una o cada uno tiene de sí mismo.

Aquí emergen dos cuestiones prioritarias para impulsar un camino hacia la inclusión de la perspectiva de género en el ámbito sindical y contribuir a la equidad entre varones y mujeres. Por un lado, la necesidad de la deconstrucción de la cultura y la identidad del sindicalismo masculino tradicional —históricamente vinculadas a la figura del trabajador y líder dirigente varón-, para dar lugar a la construcción de espacios de liderazgo por parte de las mujeres en igualdad de condiciones con los varones. Por otro, el complejo proceso subjetivo de interiorización de la problemática de género por parte de quienes dirigen las organiza- 
ciones sindicales, que requiere del reconocimiento y la desnaturalización de las inequidades y de la comprensión cabal de cuáles son sus causas.

Sin ese reconocimiento y sin la comprensión real de la perspectiva de género, es muy difícil que esta pueda ser plenamente institucionalizada o incluida de manera transversal en las políticas sindicales.

\section{Los discursos de las y los representantes sindicales de la salud sobre las desigualdades de género}

Siguiendo el planteo anterior para aplicarlo a los casos de estudio, nos preguntamos, ¿qué nivel de reconocimiento de la existencia de desigualdades de género en el ámbito laboral tienen los y las dirigentes sindicales de la salud en Argentina? ¿Cuál es su mirada sobre las diferencias en las oportunidades de acceso y en el ejercicio del poder entre varones y mujeres en el ámbito gremial? ¿Cómo incide la cuestión del lenguaje y la cultura sindical en el proceso de incorporación de la perspectiva de género en estos sindicatos?

\section{La identificación de desigualdades de género en los ámbitos laboral y sindical}

En las entrevistas realizadas a dirigentes sindicales de la salud pertenecientes al CICOP y a la FATSA dialogamos sobre las condiciones laborales y las problemáticas que enfrentan las trabajadoras y los trabajadores del sector, desde diferentes puntos de abordaje. En principio, y ante la pregunta sobre cuáles son las principales problemáticas laborales actuales, emergieron una serie de cuestiones vinculadas a los déficits salariales y de condiciones y medio ambiente laboral que son los problemas más "urgentes" de la realidad laboral del sector.

En casi la totalidad de los relatos de representantes de ambos gremios estuvo ausente la mención a desigualdades de género en esta primera aproximación. No obstante, con el devenir de las conversaciones, fueron surgiendo diversos indicadores de la existencia de situaciones profundas de desigualdad, desfavorables para las mujeres trabajadoras. Entre las y los dirigentes entrevistados se detectaron divergencias profundas en la percepción sobre la temática, en el nivel de conocimiento del significado y la implicancia de la problemática de género y en los planteos sobre las acciones y políticas necesarias para producir un cambio.

La segregación ocupacional dentro del sector es uno de los fenómenos más reconocidos: las mujeres, a pesar de ser mayoría, no acceden a algunas ocupaciones 
y son pocas las que llegan a puestos altos en la pirámide de jerarquías. Las entrevistadas y los entrevistados aluden a la concentración de las mujeres en ciertas ocupaciones, que suelen tener una carga importante de cuidado directo en sus tareas y que históricamente fueron vinculadas con los "saberes naturales" y la "vocación" de las mujeres. Y, como contraparte, refieren a su menor participación en ciertas especialidades de la medicina que poseen mayor prestigio, como la cirugía o la traumatología.

El difícil acceso de las mujeres a puestos jerárquicos, como jefaturas o direcciones, confirma la percepción de que para ellas hay más limitantes. Varias sindicalistas entrevistadas lo mencionan reiteradamente como un hecho que evidencia la existencia de obstáculos mayores en la carrera de ascenso. No aparece en ninguno de los relatos un intento de explicación de sus causas, pero sí el reconocimiento de su existencia.

Se identifican sectores masculinizados y sectores feminizados. Para los varones, las ocupaciones donde se realiza más fuerza y que poseen un prestigio mayor. Para las mujeres, las ocupaciones con menor exigencia física y que están vinculadas al cuidado directo. Esas diferencias parecen naturalizadas, son imágenes discursivas recurrentes y en muchos casos no son cuestionadas, sino que forman parte de una realidad que se menciona y se acepta como tal.

Por otra parte, al analizar la participación sindical de mujeres y varones, el reconocimiento de desigualdades es aún menor. La gran mayoría de los sindicalistas sostienen que no hay diferencias de sexo dentro de la actividad sindical, que todos y todas tienen iguales oportunidades, alegando la democracia de las organizaciones y que al ser mayoría de mujeres en la salud, ellas acceden igual o más que los varones: "yo no veo diferencias", "ellas son más y están en todos lados, igual que nosotros", "nunca tuvimos un prurito en que se incluyan mujeres, todos somos iguales".

Incluso, algunas dirigentes mujeres entrevistadas niegan la existencia de situaciones de desigualdad y plantean que la mención de diferencias de género, en sí misma genera una "discriminación" o una actitud "machista":

Yo creo que no. Es como un poco machista eso. No he sentido nunca una diferencia. Al contrario. $\mathrm{Y}$ la verdad que tenemos un grupo muy homogéneo y las diferencias que podamos llegar a tener, las conversamos. [...] Ni varón, ni mujer, ni religión, ni política. Acá por suerte todos hablamos de todo (Gladys, FATSA).

A mí no me vengan con esas cosas porque yo no me autodiscrimino. Porque para poder decir algo tengo que dar el ejemplo. [...] yo no lo he sufrido en la CGT.

[...] También porque los trato de igual a igual. También creo que va en la capacidad de cada una. Si vos empezás a autodiscriminarte, los demás siempre te 
van a discriminar. A nivel consciente o inconsciente van a marcar la diferencia. Si vos los tratás de igual a igual, lo asumen. (Laura, FATSA).

En estas frases de sindicalistas de Sanidad se entrevé un desconocimiento de cuál es el significado de la perspectiva de género, ya que es planteado por las propias mujeres con resistencia y temor a que implique colocarlas en una situación de vulnerabilidad o debilidad. Por un lado, algunas reconocían diferencias en la participación laboral de mujeres y varones en el sector, pero casi ninguna planteó la necesidad de revertirlas. Y en relación con el ámbito sindical, consideran que, o bien no existen desigualdades, o bien se dan en casos particulares, y que su solución depende mayormente de las capacidades individuales de las mujeres de enfrentarse a los varones y posicionarse de igual a igual.

Experiencias y percepciones sobre la conciliación entre trabajo remunerado, cuidado y actividad sindical

El tópico más recurrente en las conversaciones con las y los dirigentes sindicales, principalmente con las mujeres, se vincula a las dificultades de conciliación entre el trabajo remunerado en el sector salud, la tarea sindical y las responsabilidades domésticas y de cuidado. Esta cuestión emerge - a partir de algunas preguntas sobre su composición e historia familiar - como un conflicto en la vida de las mujeres por ser quienes ocupan mucho tiempo y cargan con la mayor parte de las responsabilidades dentro del hogar, las que deben conciliar con las horas dedicadas al trabajo y con el tiempo que implica la actividad sindical.

Las chicas, sobre todo las más jóvenes, están desbordadas, entre que muchas tienen dos trabajos, las enfermeras y mucamas la mayoría, y después hacerse cargo de los chicos, del marido, si tienen, porque muchas son separadas, se hace un día larguísimo, agotador. Eso es cierto que en los varones no lo ves, ellos saben que terminan de trabajar y se terminó la jornada. Es así (Entrevista a Analía, referente sindical de la FATSA, 2014).

Quienes tienen una visión más tradicional asocian la responsabilidad del cuidado de niños y niñas casi de forma exclusiva con la mujer, y al momento de pensar soluciones se dirigen a extender las licencias por maternidad y los permisos especiales a las mujeres para las tares de cuidado. El varón, desde esta mirada, aparece como un "acompańante", como alguien que atiende aquellas necesidades que las mujeres por algún motivo no pueden cubrir. Como lo plantea una dirigente a cargo de una secretaría local de la mujer: 
Por cuestiones de licencia maternal se está pidiendo una extensión. Más que nada a partir que nace. Una, por el bebé en sí, que es cuando más contacto tenga con la madre es lo mejor. Y a una también le cuesta. Y las licencias de los hombres... Claro, a veces también se necesita, por ejemplo, si hubo un embarazo de riesgo, si no tenés mucha familia, el marido tiene que cuidarte. Si el bebé nace con algún problema también. El hombre muchas veces también tiene necesidad (Entrevista a Haydeé, referente sindical de la FATSA-SSP, 2015).

Desde otro enfoque, se encuentran algunas posturas que analizan el cuidado y la conciliación con una perspectiva de género, que coloca a la mujer $\mathrm{y}$ al varón con responsabilidades similares frente al cuidado de sus hijos o de otras personas a cargo. Entonces, además de la ampliación de las licencias por maternidad y los permisos a las mujeres por lactancia y durante el embarazo, también reconocen la necesidad de ampliar los derechos de los varones en tanto padres (biológicos o adoptivos). En estos casos emergen propuestas para extender las licencias por paternidad, o buscar la igualdad en los permisos familiares y otorgar beneficios de cuidado, como las guarderías, a varones y mujeres por igual. En los relatos se observa cómo estas propuestas chocan con las limitaciones de quienes definen las políticas sindicales o legislativas:

En la Ley se estaba manejando una modificación para ampliar la licencia por maternidad o por paternidad, en la que estamos de acuerdo yo creo que todos los gremios que funcionamos a nivel provincial. Pero evidentemente no hemos convencido a nuestros legisladores porque ese proyecto no avanzó. En realidad habría que revitalizarlos pero también tenés que hacer el lobby, con los otros sindicatos y con los legisladores y las legisladoras. Una cosa que nosotros la venimos conversando, pero también es muy difícil la implementación es que definitivamente todos los lugares de trabajo haya jardines para los niños y niñas (Entrevista a Mónica, referente sindical del CICOP, 2014).

Pero más allá del reconocimiento de la problemática de la conciliación desde una mirada de género por parte de algunas sindicalistas, no es algo generalizado y no se han logrado avances en este sentido, ya que es un tema ausente en los contenidos negociados colectivamente. Son temas resistidos en general, por los sindicalistas, varones y mujeres, y los motivos pueden ser, por un lado, el desconocimiento y la ausencia de debate de dicha problemática, y por otro, la dificultad de reconocer que las responsabilidades domésticas y de cuidado no son exclusivamente femeninas como se ha instalado históricamente en nuestra sociedad. 
Una de las preocupaciones fundamentales es el tema de los cuidados. Intentar que en los sindicatos se tome como un tema prioritario. Es muy difícil, con los compańeros varones, que no lo visualizan. Igual nosotros seguimos insistiendo, hemos aprendido bastante. Insistimos con la creación de lugares de cuidado para nuestros hijos e hijas, es como el tema. Que nos permitan a las mujeres insertarnos en las mismas condiciones que los compañeros varones, ese es el tema. $\mathrm{Y}$ tampoco como un derecho que sigue siendo solo para las trabajadoras mujeres, nosotros cuando planteamos los jardines maternales lo planteamos tanto para las mujeres como para los varones (Entrevista a Alejandra, referente sindical del CICOP y la CTA, 2014).

Además, en relación estrictamente con la participación sindical, emerge con más agudeza la problemática de la conciliación como una de las principales dificultades que enfrentan las mujeres para poder participar plenamente en la actividad gremial.

Las dificultades que enfrentan las mujeres para dedicarse a la militancia sindical. Las dificultades vienen de que la mayoría de las mujeres son jefas de hogar, entonces se le dificulta por el tema de que son madre, padre, ama de casa y además trabajan, es por eso que no cuentan con el tiempo suficiente que en realidad demanda militar (Entrevista a Mónica, referente sindical de la FATSA, 2014).

Conciliar las obligaciones de la vida familiar con las obligaciones del trabajo, más las obligaciones de la política y o del gremio, difícil. Nosotras venimos con la idea de que el ámbito sindical es más complicado, y no es que lo sea en sí mismo sino que está ocupado fundamentalmente por varones, entonces las mujeres tenemos que estar lidiando para ocupar nuestros lugares (Entrevista a Mónica, referente sindical del CICOP, 2014).

Pero más allá de las menciones de algunas dirigentes, el problema de la conciliación no es tomado por el sindicalismo como un eje de acción, como un disparador de políticas o de demandas gremiales.

Desde la experiencia personal, muchas sindicalistas del cicop y Sanidad hacen referencia a las complicaciones que tuvieron a lo largo de sus trayectorias laborales y sindicales para conciliar los tiempos que implica el trabajo gremial con la vida familiar y conyugal.

Nosotras trabajamos muchas horas. Cuando hay conflicto no tenemos horario, no tenemos fines de semanas. Estamos ahí la secretaria general y yo, todo el tiempo con los trabajadores. Porque si hay una huelga están permanentemente 
hostigando a la gente. Y no es fácil. Y a veces, ingrato. Y yo ahora puedo porque soy sola y mis hijos grandes, antes se me recomplicaba... hoy a las compañeras con marido e hijos se les recontracomplica, por eso cuando hay conflictos extensos nos quedamos nosotras que estamos solas y no tenemos horarios, o los compańeros varones que tienen más libertad (Entrevista a Gladys, referente sindical de la FATSA, 2014).

La cuestión afectiva y los conflictos matrimoniales son dimensiones insoslayables cuando se indaga en las historias de las mujeres que participan de la vida sindical y en los casos que no fue un problema personal lo mencionan como "una suerte" por haber tenido una pareja que supo "acompañar y compensar esos tiempos" que ellas dedicaban a dicha tarea.

Frases como "fue una guerra con mi marido" o "me llevó el costo de mis hijos" demuestran cierta culpa que las propias mujeres se adjudican por haber decidido dedicar parte de su tiempo a las actividades sindicales, que en muchos casos se suman a la jornada laboral en las clínicas u hospitales, como sucede con gran parte de las profesionales del cicop, que no cuentan con licencia gremial para dedicarse exclusivamente a lo sindical.

Una situación que se menciona de forma recurrente es la gran cantidad de mujeres que actualmente se dedican a la actividad gremial y ocupan puestos de conducción que están "solas", por diversos motivos, sin parejas ni hijos o con hijos grandes de edad, situación que aparece como un conflicto desde lo afectivo y lo económico, pero se visualiza como un punto positivo porque les da "libertad".

En contraste con los testimonios de las dirigentes mujeres, en ningún caso de los varones entrevistados se evidenció un malestar, una dificultad o la vivencia de conflictos familiares vinculados a su dedicación a la actividad sindical. Quienes hicieron referencia a la problemática de la conciliación lo mencionaron como algo que les sucede exclusivamente a las mujeres:

Uno ve a algunas compañeras, a las más jóvenes, y piensa "¡cómo hace esta mujer?”, hay una compañera por ejemplo que tiene tres hijos de menos de doce, y viene a todas las reuniones, no falta a un plenario, a un congreso, ella siempre al pie del cañón, y también es una madre impecable, eso me consta (Entrevista a Carlos, referente sindical de la FATSA, 2015).

Yo veo que las compañeras hacen milagros con sus vidas, muchas de ellas con hijos chiquitos, a veces las ves por acá con sus bebés, que ya todos los conocemos, a veces otras compañeras o nosotros mismos se los cuidamos un rato o se quedan en las reuniones, así entre todos colaboramos, de eso se trata (Entrevista a Claudio, referente sindical de la FATSA, 2015). 
A pesar de que las mujeres están cada vez más presentes en el ámbito laboral, político y sindical y a pesar de que hay cada vez más varones que cuidan y dedican tiempo a sus hijos, la inercia de considerar el cuidado como cuestión de mujeres persiste, y eso se evidencia en los discursos de muchos dirigentes sindicales varones y mujeres. No solo se considera un problema exclusivo de las mujeres, sino que cuando se toca el tema desde la mirada institucional de cada sindicato, la importancia de esta cuestión se desdibuja.

Las mujeres sostienen que la dinámica de los tiempos y prioridades sindicales "la siguen marcando los varones" que no tienen en cuenta "los tiempos de las mujeres" ni se adaptan a los "tiempos familiares". En general, no se plantea desde las y los dirigentes sindicales un cuestionamiento a la división sexual de las responsabilidades familiares, salvo por parte de las mujeres vinculadas a las secretarías de género. Desde ese lugar, en ambos sindicatos se han organizado charlas o encuentros en los que se debate con dirigentes, delegadas y afiliadas el reparto desigual de roles sociales y familiares para varones y mujeres y se plantean las posibles políticas de cuidado a implementar para mejorar esa desigualdad. Sin embargo, según los testimonios recabados, los debates no logran permear las posiciones o las estructuras de pensamiento de las y los dirigentes sindicales al respecto, ya que no han trascendido los ámbitos de discusión de charlas o congresos, donde la mayoría de las participantes son mujeres, tampoco han ganado un lugar en las discusiones paritarias y aún no se han transformado en programas o proyectos que los abarquen.

La autodefinición de las propias mujeres sindicalistas como las únicas responsables del cuidado de sus hijos e hijas, así como la propia percepción de los dirigentes varones como ajenos a esa responsabilidad claramente se vincula a la construcción de la identidad de género, que históricamente ha colocado a las mujeres como cuidadoras y a la masculinidad en oposición o como negación de esa figura femenina de cuidado. En consecuencia, dentro del ámbito sindical los problemas de la conciliación trabajo/cuidado siguen siendo cuestiones exclusivas de las mujeres que trabajan y de las mujeres que participan en la actividad gremial. En el caso de las sindicalistas, el problema de la conciliación, que es transversal a todas las trabajadoras, se magnifica al sumarse el tiempo dedicado al trabajo gremial, a los tiempos de trabajo remunerado en el mercado y no remunerado en el hogar.

\section{Lenguaje, cultura masculina y construcción de poder en los sindicatos}

Las estructuras de pensamiento interiorizadas por quienes participan en las organizaciones sindicales, en su conjunto, dan forma a un modo institucional de abordar la problemática de género. Pero dentro de esa estructura hay 
divergencias, enfrentamientos y conflictos de poder que se vinculan al género. Si pensamos las relaciones de género en el sindicalismo en cuanto prácticas de culturas de militancia, en cuanto habitus, en el sentido de Bourdieu, que mueve a los agentes en el campo sindical, podemos visualizar que mujeres y varones se mueven e interactúan con sus modos específicos de hacer y decodificar la realidad. Las diferencias de género serían instrumentos políticos utilizados en el juego del poder dentro de la estructura sindical, y reivindicados, consciente o inconscientemente, para mantener a las mujeres en su lugar "natural", o sea, para ejercer una dominación (Bourdieu, 1997; Ostronoff, 2007).

Incluso en los sectores más feminizados, como la salud, las figuras metafóricas de la fuerza y la dureza permean la masculinidad y operan a través de las más variadas formas de cultura del trabajo, influenciando profundamente los modos de la práctica sindical. Las estructuras masculinas, tanto conscientes como inconscientes, contribuyen a desarrollar una conciencia sindical característica (con un sesgo de género profundamente escondido), en la que la masculinidad emerge como un poder en sí mismo (Acker, 1990; Ledwith, 2012).

En los discursos de las y los representantes sindicales de Sanidad se identifica fácilmente cómo la cultura sindical hegemónica continúa siendo aquella que reproduce prácticas, discursos, lenguajes y modos de analizar la realidad con un sesgo marcadamente masculino, reproduciendo la forma tradicional de diferenciación de género.

Por un lado, que las mujeres adopten conductas y modos de decir "típicos de los varones" para que ellos las consideren como "uno más" aparece muchas veces como la solución para su integración en un espacio tan permeado por prácticas "masculinizadas".

Yo sí lo padezco. Porque yo me tengo que pelear con todos los directivos. Y siendo trabajadora, mujer, hay que demostrar la fuerza, hay que mostrar los dientes si no te tratan de débil. Tenés que pararte de igual a igual para que te respeten. (Entrevista a Laura, referente sindical de la FATSA, 2014).

A los hombres le cuesta trabajar con nosotras como pares, hasta inclusive a veces me da la impresión que sienten miedo de que ganemos lugar. Siempre tenemos que estar peleándola. [...] todavía tienen en su lenguaje algunas cosas como que no nos tienen tan en cuenta como a los hombres. [...] todavía no están interiorizados. Te das cuenta en el lenguaje, todavía nos falta, pero bueno, ya estamos participando (Entrevista a Norma, referente sindical de la FATSA, 2014).

Los estereotipos de género no tardan en emerger cuando se habla de los modos de actuar de las mujeres y los varones dentro del ámbito sindical. Las 
mujeres se visualizan como más dóciles, sensibles y menos formadas para la lucha gremial. Los varones se posicionan como más duros y más preparados para esta actividad, que parece ser muchas veces hostil, y parecen ser quienes ceden espacios para que ellas puedan integrarse.

Acá somos muchas mujeres, la mayoría por enfermería. [...] vocación pasa en la mujer por una cuestión de sentimiento, de vibra. Y eso se ve también en cómo trabajamos dentro de lo sindical, somos más de escuchar, de acompańar, y los muchachos son más del choque, de ir a enfrentar digamos (Entrevista a Haydeé, referente sindical de la FATSA-SSP, 2015).

El verdadero conductor tiene que seducir. Yo creo que a la mujer tenés que seducirla como siempre pasa en la vida. Para que sea parte, para que se sienta cómoda, para que pueda decidir sobre determinada cuestión. Y que se pueda equivocar, que está bien [...] Perón cuando nos hablaba siempre nos decía compañeros, no decía compañeros y compañeras. No es una cuestión de género, hablar de compañero (Entrevista a Sergio, referente sindical de la FATSA, 2014).

Incluso en mensajes institucionales vinculados al Día de la Mujer se identifica la reproducción de estereotipos de género, como se observa en esta frase publicada en la página web de Sanidad: "Redescubramos nuestra esencia femenina, que nos permite mirar el mundo con profunda sensibilidad. Respetemos nuestra naturaleza biológica, que abre la posibilidad que la vida pase a través de nosotras. Sostengamos la valentía, el empuje y la confianza para transformar la realidad, aprendiendo lo necesario y entregándonos ardorosamente con amor a cada tarea". La esencia femenina es reivindicada desde el lado de la sensibilidad y el amor que se presentan como valores fundamentales y necesarios por tratarse de una actividad vinculada al cuidado. Sin embargo, parecen ser valores y características solamente enaltecidas para las mujeres.

En el CICOP, por su parte, identificamos una intención más generalizada de incorporar la mirada de género dentro del gremio desde la comisión directiva. Sin embargo, aún persisten dificultades para instalar la perspectiva de género y la comprensión de la problemática es muy débil, sobre todo en las y los dirigentes de las seccionales locales.

Hay como un desconocimiento porque no entendés cuando hablás de la perspectiva de género, vos decís “¿de qué están hablando?” Bueno, creo que eso es información, es formación interna. Porque tenés que empezar a darte cuenta de esa realidad, de lo que es la perspectiva de género (Entrevista a María Inés, referente sindical del CICOP, 2014). 
Ese discurso del desconocimiento se repite bastante, y en algunos casos hasta se niega la necesidad de plantear la problemática de género como un tema sindical, alegando que no visualizan a su alrededor desigualdades que requieran un tratamiento especial. En el CICOP existe un grupo que trabaja fuertemente desde esta perspectiva, pero incluso en sus propias palabras manifiestan que falta mucho y que las "peleas por el reconocimiento con los compañeros son constantes". Además, aquí también la reproducción de estereotipos dificulta la aceptación plena de las mujeres como dirigentes sindicales. Si bien en el discurso todas y todos son descritos como iguales, en la práctica las mujeres en roles de liderazgo son juzgadas muchas veces con prejuicios o con dudas, solo por el hecho de ser mujeres.

Resistencias... montones. Discusiones, montones. Me parece que nos pasa lo mismo que pasa siempre, que cuando es una mujer la que está en ese lugar tan alto, esa exposición tan alta, no solamente la alaban, también la critican y también le critican cosas no solamente que se puede haber equivocado, hay cosas que se las adjudican por ser mujer (Entrevista a Mónica, referente sindical del cicop, 2014).

Como mujer es como que hay un juzgamiento, una presión mayor. Sí, eso existe, en algunos lugares más que en otros. En el caso de lo gremial es más jodido, cuando tenés que llegar a la cúspide. No es un tema el trabajo, el trabajo gremial la mujer lo hace, creo que es un problema de disputas por espacios de poder y a las mujeres se les hace más cuesta arriba, tienen que demostrar mucho más (Entrevista a Mirta, referente sindical del cicop, 2014).

A pesar de que en el cicop el reparto de los lugares de dirección es bastante igualitario y que incluso cuantitativamente las mujeres son más, los discursos denotan la persistencia de la concepción del sindicalismo como un espacio con reglas y dinámicas masculinas, a las que las mujeres deben adaptarse o pelear para romperlas. Es una pelea que se está dando, pero destruir los preconceptos contra las mujeres en el medio sindical, y en la vida política en general, es un proceso largo que es parte de un proceso de cambio cultural.

Muchas de las dirigentes del cicop reconocen que se ha avanzado bastante en los últimos años, en la instalación de la problemática de género en el sindicato y, principalmente, en las actitudes y concepciones de los dirigentes varones y algunas mujeres que antes negaban la existencia de desigualdades y en la actualidad acompañan o "al menos aceptan" que es necesario el enfoque de género. En el camino que falta por recorrer para incorporar plenamente la problemática de género al sindicato, no solo como un tema aislado sino integrado a la política gremial, la comprensión del significado del enfoque de género es 
fundamental, y ese paso aún no se logró de forma generalizada, como lo reconoce la secretaria de Género del CiCOP:

Yo creo que todavía hay muchas compañeras que no logran tener la mirada de género y comprender por qué ponemos en discusión esto de las diferencias que se viven en la sociedad con respecto a los varones y las mujeres, cómo se expresan en los distintos ámbitos de la vida, y por ahí en particular en los lugares de trabajo (Entrevista a Mónica, referente sindical del Cicop, 2014).

Y nuevamente emerge la cuestión del lenguaje, como eje fundamental en la cultura sindical. La aceptación (tácita o explícita) de un lenguaje sexista y la reproducción de modos de decir que mencionan a los hombres y ocultan a las mujeres, reproducen las desigualdades y las asimetrías de poder dentro de una organización, que desde sus orígenes se pensó y se gestionó desde la mirada de los varones, negando la presencia de las mujeres.

El lenguaje, como parte de la cultura, transmite definiciones, posiciones, imágenes y símbolos que forman parte de las estructuras de pensamiento de las personas y que expresan la diferencia de género, la mayoría de las veces reforzando las desigualdades y con menos frecuencia oponiéndose a ellas, resistiendo.

Algunas mujeres del Cicop se muestran conscientes de la importancia del lenguaje, por eso un eje de trabajo para incorporar el enfoque de género pone el énfasis en cambiar las palabras y las referencias que se utilizan desde el sindicato.

A medida que empezó a transitar el género nos dimos cuenta cómo el lenguaje también te discrimina, te separa, no te nombran. Pero bueno, nosotros llevamos como seis ańos trabajando en esto, y en el Consejo Directivo todavía nos discuten cuando les decimos que queremos que, cuando hagan la reforma del estatuto, incluyan el tema del lenguaje. Y por supuesto que también les cuesta... en las comunicaciones oficiales. Aunque se ha reformulado bastante, en todas las comunicaciones hay que nombrar también a las mujeres. Porque bueno, está muy instalado esto de que si vos decís "los trabajadores están nombrando a las mujeres". La discusión del lenguaje, el por qué del lenguaje, también es una cosa pendiente (Entrevista a Mónica, referente sindical del cicop, 2014).

A pesar de tener una presencia numerosa en los sindicatos (en el cicop las mujeres cubren el 50\% de los cargos electivos y en Sanidad el 30\%, respondiendo a la Ley de Cupo Sindical), las mujeres tanto en el cicop como en Sanidad no terminan de conquistar los espacios de poder, salvo excepciones. En los modos de describir los avances logrados en términos de mayor participación, 
en las palabras utilizadas por parte de los dirigentes varones y en los discursos de las propias mujeres, siguen marcándose diferencias que posicionan a los varones como los dirigentes "naturales", a la vez que niegan esa distinción. Y, a pesar del reconocimiento de la existencia de problemáticas de género (cuyo tratamiento es más amplio y abarcativo en el CICOP), se trata de un tema que aún no se integra plenamente a la política sindical y su abordaje continúa separado del resto de las actividades de los sindicatos.

\section{Reflexiones finales}

Del análisis presentado se desprende que en ninguno de los dos sindicatos se ha desarrollado una visión homogénea sobre la cuestión por parte de sus representantes. En ambos existen iniciativas y grupos de sindicalistas que ponen el cuerpo, la voz y el tiempo para instalar la problemática de género en el debate y en la acción sindical, y se han demostrado adelantos en ese sentido. Pero las resistencias y los obstáculos aún son profundos y muchos provienen de las dimensiones culturales y subjetivas que impiden romper con la dominación y los modos de hacer masculinos dentro del ámbito sindical.

Algunas de las dificultades encontradas para incorporar la problemática de género son de índole estructural y pueden ser vinculadas a las rigideces históricas de las organizaciones. En ese punto, el CicOP se muestra más flexible a través de los discursos de sus representantes, que cuestionan con más fuerza las desigualdades relacionadas al género y los mecanismos tradicionales de poder sindical. En Sanidad, el debate crítico en esa dirección solo está presente entre algunas de sus dirigentes que muestran una trayectoria extensa de trabajo en la temática.

Otras dificultades se vinculan a factores externos, sociales y políticos, relacionados con la persistencia en la sociedad de mecanismos de discriminación hacia las mujeres, la resistencia frente a los avances en la igualdad con los varones y la reproducción de estereotipos de género. Estos últimos se encuentran íntimamente ligados a los procesos culturales y subjetivos que atraviesan a la organización y a sus integrantes.

Los sindicatos funcionan en un marco social, cultural y económico que los contiene y condiciona. Todas las instituciones con las que interactúan - como los lugares de trabajo, la familia, los ámbitos educativos, las instituciones estatales - contribuyen de uno u otro modo a la reproducción de roles diferenciados para mujeres y varones. Por lo tanto, las coyunturas y los paradigmas culturales imperantes influyen notablemente en la posibilidad de cambio, más allá de las rigideces propias de la institución sindical. 
Factores internos y externos a la organización, objetivos y subjetivos, colectivos e individuales, se conjugan dando lugar a una determinada configuración institucional, dentro de la que se inserta la problemática de género. La clave del cambio es la cultura y, como todo cambio, no está exento de conflictos y enfrentamientos entre las viejas formas de ser, hacer y decir, profundamente arraigadas, y los nuevos modos que intentan desplazar los anteriores.

Hemos hecho el recorrido de nuestra investigación siguiendo la premisa de que, tal como lo plantea Bourdieu, el orden social y las relaciones de género son tan fuertes que se imponen a los sujetos como un orden establecido, en el cual los roles se naturalizan, se hacen cuerpo, son legitimados por símbolos, discursos y normas culturales, generando cierta predisposición a actuar, sentir y pensar de un modo determinado. Pero que más allá de su fuerza, siempre existe una posibilidad de resistencia, de toma de conciencia frente a lo impuesto, un modo de desnaturalizar y cuestionar el orden establecido.

En la experiencia del cicop y Sanidad observamos la existencia de sujetos emergentes (en el sentido planteado por Zemelman), esas voces que se elevan con nuevos modos de decir y con nuevos temas, a través de los cuales asoman nuevas formas de actuar, nuevas costumbres y discursos, que inician la configuración de "culturas sindicales emergentes".

El camino ya está abierto y las viejas formas, costumbres y discursos, conviven ya con nuevas formas de ver la realidad, con nuevos discursos y nuevas "culturas sindicales". El trabajo más difícil de quienes dedican parte de su actividad sindical a instalar la perspectiva de género, puede ser romper con el sistema binario de pensamiento (varón-mujer), lograr que se cuestionen los estereotipos y la naturalización de la división sexual del trabajo que encasilla a las mujeres y a los varones en roles estancos dentro de los diferentes ámbitos de actuación en la sociedad.

Un profundo cambio cultural que contribuya a la interiorización de la perspectiva de género es una condición necesaria para que emerja una nueva dinámica de poder de los sindicatos, más inclusiva e igualitaria, para que se amplíen los contenidos de sus políticas y que pueda generarse un avance considerable hacia la transversalidad del enfoque de género. El trabajo de un grupo por generar la sensibilidad y la comprensión sobre las desigualdades de género es necesario aunque no suficiente para mover las estructuras de pensamiento instaladas. La construcción de nuevas subjetividades es un proceso lento, que debe ser acompañado por un cambio en la sociedad, impulsado por políticas e instituciones y sustentado por las prácticas cotidianas de quienes interactúan en dichos espacios.

Pero como dijimos, el camino está abierto, y en los sindicatos existen intenciones y propuestas de cambio, se ha comenzado a cuestionar con fuerza — por 
parte de algunas mujeres - la estructura de dominación masculina y se ha reconocido formalmente la necesidad de incluir la problemática de género en las políticas sindicales.

El sector de la salud, por su composición mayormente femenina, se presenta como un ámbito propicio para instalar una nueva visión y prácticas más igualitarias en términos de género. Uno de los desafíos radica en lograr romper con las viejas estructuras y limitaciones del pensamiento, tanto entre las mujeres como entre los varones que trabajan en la defensa de los derechos de las trabajadoras y los trabajadores del sector.

\section{Referencias}

Abramo, L. \& Rangel, M. (2003). Negociación colectiva y equidad de género en el contexto del Mercosur. En E. De la Garza Toledo \& C. Salas (Comps.), NAFTA y MERCOSUR Procesos de apertura económica y trabajo (pp. 215-242). Buenos Aires: CLACSO.

Acker, J. (1990). Gendering Organizational Theory. En A. J. Mills \& P. Tancred (Comps.), Gendering Organizational Analysis (pp. 248-260). Londres: Sage.

Ariza, M. \& De Oliveira, O. (1999). Género, Trabajo y Familia: consideraciones teórico metodológicas. Nueva Sociedad, (164), 70-81.

Aspiazu, E. (2016a). Heterogeneidad y desigualdades de género en el sector Salud: entre las estadísticas y las percepciones sobre las condiciones de trabajo. Revista Pilquen, Sección Ciencias Sociales, 19(1), 55-66.

Aspiazu, E. (2016b). La inclusión de la perspectiva de género en el ámbito sindical como medio para mejorar las condiciones laborales, las posibilidades y el bienestar de las mujeres trabajadoras. Estudio de casos en asociaciones gremiales del sector salud. En GT2.6 Los significados de las relaciones de género en la actualidad del mundo del trabajo latinoamericano. Actas del VIII Congreso ALAST. Buenos Aires: UBA.

Aspiazu, E. (2014). Equidad de género, mercado de trabajo y sindicalismo en la Argentina. Realidad Económica, (284), 10-36.

Bonaccorsi, N. \& Carrario, M. (2012). Participación de las mujeres en el mundo sindical: Un cambio cultural en el nuevo siglo. La Aljaba, 16.

Bonder, G. (1998). Género y subjetividad: avatares de una relación no evidente. En S. Montecino \& A. Obach (Comps.), Género y Epistemología: Mujeres y Disciplinas (pp. 29-45). Santiago, Chile: Universidad de Chile/Lom. 
Bourdieu, P. (2000 [1998]). La dominación masculina. Barcelona: Anagrama.

Bourdieu, P. (1997). Razones prácticas. Sobre la teoría de la acción. Barcelona: Anagrama.

Bourdieu, P. (1991). El sentido práctico. Madrid: Taurus.

De Barbieri, T. (1996). Certezas y malos entendidos sobre la categoría género. En L. Guzmán Stein \& G. Pacheco (Comps.), Estudios básicos de derechos humanos IV (pp. 47-84). San José de Costa Rica: Instituto Interamericano de Derechos Humanos/Comisión de la Unión Europea.

Díaz, E. \& Goren, N. (2011). La negociación colectiva como mecanismo de promoción de la equidad de género y diversidad. Buenos Aires: СЕмYT.

Iranzo, C. \& Ritcher, J. (2003, abril-junio). El tema de género en las convenciones colectivas en Venezuela. Revista Venezolana de Gerencia, (8).

Lamas, M. (2000, enero-abril). Diferencias de sexo, género y diferencia sexual. Cuicuilco, 7(18), 2-24.

Lamas, M. (1999, julio-septiembre). Usos, dificultades y posibilidades de la categoría género. Papeles de Población, 5(21), 147-178.

Ledwith, S. (2012). Gender politics in trade unions. The representation of women between exclusion and inclusión. Transfer, 18(2), 111-128.

Libchaber de Palomino, M. (2011). Conflicto Laboral y Género. La movilización colectiva de las mujeres y barreras para su participación en las direcciones sindicales. (Documento de Trabajo, Colección Generar Investigación). Buenos Aires: Consejo Nacional de la Mujer.

Lupica, C. (2010). Trabajo decente y corresponsabilidad de los cuidados en Argentina. Santiago de Chile: оIт.

Novick, M. \& Galín, P. (2003). Flexibilidad del mercado de trabajo y precarización del empleo. El caso del sector salud. En Organización Panamericana de la Salud, Observatorio de RRHH en Salud en Argentina. Información estratégica para la toma de decisiones (pp. 11-90). Buenos Aires: ops/oms.

Novick, M., Trajtenberg, D. \& Heredia, M. (2005). Argentina: negociación colectiva y equidad de género, 1991-2000. En L. Abramo \& M. Rangel (Eds.), América Latina, negociación colectiva y equidad de género. Santiago, Chile: OIT.

Okin, S. (1989). Justice, gender, and the family. Nueva York: Basic Books.

E. L. Aspiazu | Desigualdades de género en los discursos de la dirigencia sindical argentina. Estudio de caso en el sector salud | Perfiles Latinoamericanos, 27(53) | FLACso México | Dor: 10.18504/pl2753-008-2019 
Ostronoff, L. (2007). Poder, Genero e Identidades. Um novo momento no sindicalismo. San Pablo: Fundação Escola de Sociologia e Política de São Paulo.

Pastor, R. (1994). Mujeres, género y sociedad. En L. Knecher \& M. Panaia (Comps.), La mitad del país. La mujer en la sociedad argentina (pp. 35-62). Buenos Aires: Centro Editor de América Latina.

Pautassi, L. (2006). El empleo en salud en la Argentina. La sinergia entre calidad del empleo y calidad de la atención. En M. N. Rico \& F. Marco (Coords.), Mujer y empleo. La reforma de la salud y la salud de la reforma en Argentina. Buenos Aires: CEPAL/GTZ/Siglo XXI.

Rigat Pflaum, M. (2008a, noviembre-diciembre). Gender mainstreaming: un enfoque para la igualdad de género. Nueva Sociedad, (218), 40-56.

Rigat Pflaum, M. (2008b). Los sindicatos tienen género. (Working paper). Buenos Aires: Fundación Friedrich Ebert.

Sandoval Robayo, M. L. (2002). Pierre Bourdieu y la teoría sobre la dominación masculina. Revista Colombiana de Sociología, VII(L), 55-73

Scott, J. (1990). El género: una categoría útil para el análisis histórico. En J. Amelang \& M. Nash (Comps.), Historia y género: las mujeres en la Europa moderna y contemporánea. Barcelona: Alfons el Magnanim.

Tobío, C. (2012, mayo-agosto). Cuidado e identidad de género. De las madres que trabajan a los hombres que cuidan. Revista Internacional de Sociología, 70(2), 399-422.

Todaro, R. (2004). Introducción general. En R. Todaro \& S. Yáńez (Eds.), El trabajo se transforma. Relaciones de producción y relaciones de género (pp.15-34). Santiago, Chile: Centro de Estudios de la Mujer.

Touraine, A. (1997). ¿Podremos vivir juntos? México: FCE.

Trajtemberg, D. (2009). Negociación colectiva durante 2003-2007, un análisis desde la perspectiva de género. $9^{\circ}$ Congreso ASET. Buenos Aires.

Wainerman, C. \& Geldstein, R. (1990). Condiciones de vida y trabajo de las enfermeras en Argentina. (Cuadernos del cenep, núm. 44). Buenos Aires: Centro de Estudios de Población.

Zemelman, H. (1994). Sobre la importancia de las realidades que se ocultan. Revista Tramas, (6), 9-20. 